\title{
TIME ANALYSIS OF HARD AND SOFT BOLUS PROCESSING
}

\author{
Lucie Himmlova $^{\mathrm{a} *}$, Tomas Goldmann ${ }^{\mathrm{b}}$, Stefan Ihde ${ }^{\mathrm{c}}$, Svatava Konvickova ${ }^{\mathrm{b}}$
}

${ }^{a}$ Institute of Dental Research $1^{\text {st }}$ Medical Faculty of Charles University and General Medical Hospital, Vinohradska 48, 12021 Prague 2, Czech Republic

${ }^{b}$ Czech Technical University in Prague, Laboratory of Biomechanics, Technicka 4, 16667 Prague, Czech Republic

c Clinic of Dentistry, Faculty of Medicine and Dentistry, Palacky University, Olomouc, Palackeho 12, 77200 Olomouc, zech Republic

*e-mail:himmlova@seznam.cz

Received: September 14, 2007; Accepted: November 5, 2007

Key words: Mastication/Kinematics/3D Motion Analysis/Bolus processing/Experiment in vivo

Objective: Clinical observations and mathematical models show that dental implants are influenced by the magnitude of loading. Therefore, the knowledge of mandible movement during mastication is important to assess occlusal and masticatory force vectors. The purpose of this study was to detect the path of movement of the lower jaw and to distinguish stages of mastication, duration of bolus processing and peak amplitude of mastication.

Method: Motion analysis was used to record three-dimensional mandible movements. Individualized sensors were rigidly attached to the mandible of 51 study participants. At the beginning of the measurement, all subjects were asked to move the mandible in extreme positions (maximal opening and maximal lateral movements). Then, each subject masticated a bite of hard and soft food. Duration of bolus mastication and peak amplitude of mastication movement in mesio-distal, cranio-caudal and vestibulo-oral axes related to peak amplitude of marginal movements were evaluated for each subject. The chewing record of each subject was divided into three phases (chopping, grinding and swallowing), and the duration of mastication and number of closing movements were evaluated.

Results: The findings of this pilot study suggest that masticatory movements vary in individuals. Bolus character influences the process duration, but not the frequency of closing movements. Neither gender nor age had any influence on either the time or frequency of bolus processing.

Conclusion: Relationships to directions and magnitudes of acting chewing force should be more precisely examined since transversally acted forces during grinding are important factors in tooth/implant overloading.

\section{INTRODUCTION}

Mastication is a set of bite movements whereby nutrient is processed. The trajectory of these motions affects the direction and magnitude of masticatory force. This trajectory is markedly influenced by an individual's unique chewing habits ${ }^{1}$.

Mastication consists of several repetitive movements. First, food is bitten. Next, a detached bolus is transported posteriorly towards the pharynx during the fine crushing. Then, the bolus is mixed with saliva and is finally swallowed $^{2,3}$. Throughout mastication, the lower jaw midline moves along an elliptically shaped curve ${ }^{4}$. The size and the shape of this curve vary depending on the bolus processing phase (chopping, grinding and swallowing) and bolus character (soft, hard, fibrous, etc.) ${ }^{4,5}$.

Masticatory movements during function are technically an example of a kinematically and mechanically indeterminate system. Jaw movements are produced via masticatory muscles. While these muscles are activated heterogeneously $^{6}$, each muscle is able to influence more than one degree of freedom ${ }^{7}$. All muscles act together and generate a resultant force and torque (six degrees of freedom) with respect to the lower jaw ${ }^{8}$. The distribution of forces and torques necessary to perform any movement over different parts of the masticatory process is not known. Consequently, the system is mechanically redundant.
The mandible and the skull are able to move with respect to each other and are guided by two temporomandibular joints. The mandibular condyle articulates with the articular fossa of the temporal bone in each joint. The articular capsule is slack (freely moveable). Owing to this construction both joints allow for movements with six degrees of freedom (rotation - detrusion (opening) and elevation (closing), lateral movements - laterotrusion, mediotrusion and translation - protrusion, retrusion). If joint surfaces are assumed to be immovable and maintain contact all the time, the mandible is still able to move with four degrees of freedom ${ }^{9}$. Jaw movements in particular anatomical directions can be defined by the three dimensional path of a point that is rigidly connected with the lower jaw. The movement of this point can be scanned and its path can be reconstructed by the motion analysis technique ${ }^{10}$.

This pilot study was designed to detect the path of lower jaw movement during the mastication, to determine the duration of the processing of one bite depending on its character (hard and soft aliment), and to analyze the timing of the chewing. Knowledge of mandible movement during mastication is important in determining the principal anatomical direction during closing movements and the resultant direction of the loading during mastication. For these reasons the following hypotheses were tested: 
I. The duration of hard bolus processing is longer than for soft bolus $(\Sigma t(H)>\Sigma t(S))$,

II. The duration of each stage of hard bolus processing is longer than that for the soft bolus $(t 1(H)>t 1(S)$, $t 2(H)>t 2(S), t 3(H)>t 3(S))$,

III. The frequency of closing movements of hard bolus processing is greater than that for soft bolus $(f(H)>$ $f(S)$ ),

IV. The duration of bolus processing for men is longer than that for women - influence of gender,

$\mathrm{V}$. The duration of bolus processing is longer for older people - influence of age.

\section{MATERIALS AND METHODS}

Motion analysis ${ }^{10}$ was used to assess three-dimensional (3D) mandible movements. Individual sensors were designed for each subject to trace mandible movements. Each sensor made of dental wire was rigidly attached to the lower front teeth of each subject using a dental silicon impression material. The middle of the sensor was situated over the lip, and the methylmethacrylate resin marker at the end of the sensor served as a mandible position-reading instrument (Fig. 1). Additionally, black paper skin markers were placed on each subject's face above the eyebrows, on the nose dorsum and above the upper lip. These markers were used to define the local coordinated system where the motion of the sensor was observed. The $x, y, z$ coordinates (Fig. 2) represent mandibular movement in vestibulo-oral directions (laterotrusion, mediotrusion), cranio-caudal (closing, opening) and mesio-distal (protrusion, retrusion), respectively. The origin of the local (nonstationary) coordinated system was placed on the nose dorsum marker. Kinematical transformation relations between the primary (stationary) coordinated system and the local (nonstationary) coordinated systems were determined by means of a kinematical transformations matrix technique.

The motion of the markers and the sensor was mark scanned by three SONY DCR-TRV900E digital video camera recorders. Each recorder was placed such that all markers and the sensor were visible; the shutter was used for the synchronization. Recorders were calibrated using a uniquely constructed calibrating cage during the scanning. The synchronization of video records and the 3D motion reconstruction were performed by the direct linear transformation (2D video records read from 3 different positions in real time give a 3D path of sensor placed on lower jaw ${ }^{11}$ ). The raw trajectory result processing was performed by software APAS (Ariel Dynamics, Inc., SAN DIEGO, CA) system. Final results and kinematical transformations between coordinated systems were evaluated by software MATLAB (The MathWorks, Inc, Natick, MA).

At the beginning of measurement all subjects were asked to move the mandible into extreme positions (maximal opening, latero- and mediotrusion). Then, each subject (21 men, 30 women) took one bite of a hard food (nuts $-\mathrm{H}$ ) and started to masticate. The same process

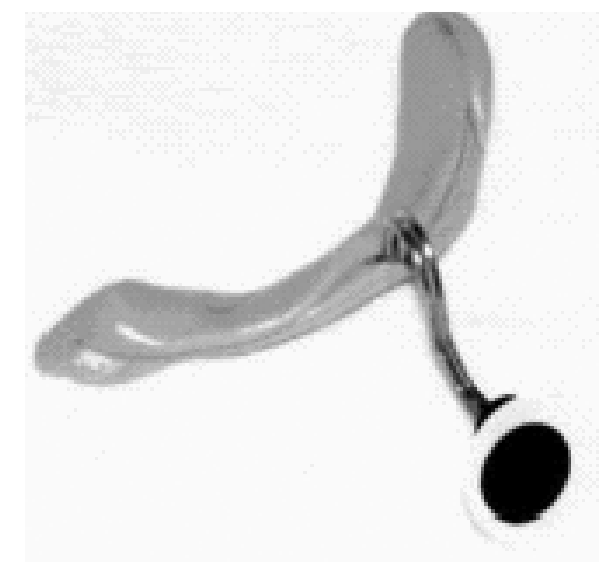

Fig. 1. Example of sensor.

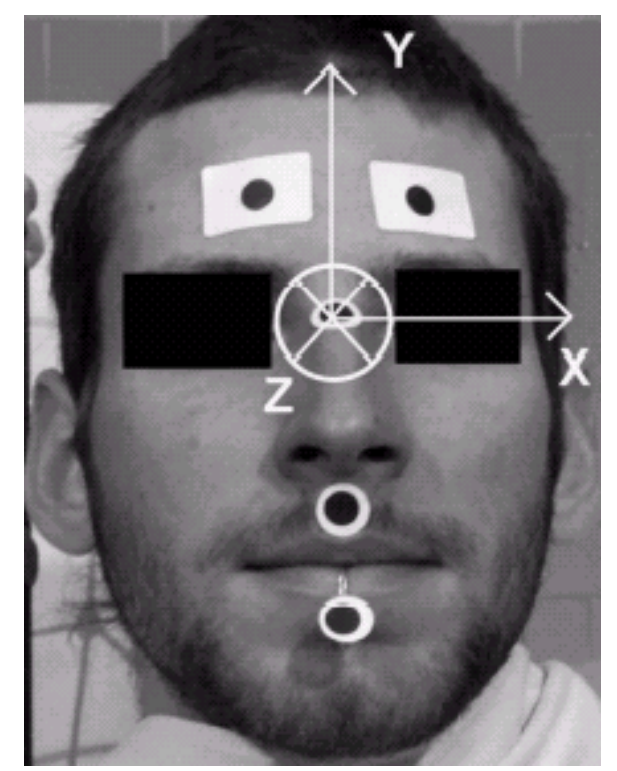

Fig. 2. Illustration of local coordinated system, skin markers and sensor.

was repeated with soft food (pastry - S). The size of the bolus varied by individual. There was no drinking during the whole experiment to prevent bolus softening or dilution. The path of the sensor was graphically expressed for each subject and for both measured motions (hard bite (H) and soft bite (S) (Fig. 3).

The each curve of the mandible movement trajectory was segmented into three phases (chopping, grinding and swallowing). The total duration of bolus mastication (hard - $t H$; soft - $t S)$, the duration of each of three parts $(t 1$, $t 2, t 3$ ) and the frequency of closing movements (f) were counted using these curves. Also peak amplitudes of masticating movement (in percent) in $\mathrm{x}, \mathrm{y}$ and $\mathrm{z}$-axis related to peak amplitudes of marginal movements (Amp $\mathrm{H}$ - nuts, Amp S - pastry) were evaluated for each patient.

All measured quantities were averaged; maximal, minimal and standard deviation (SD) values were calculated (Tab. 1 and 2). Data were analyzed using the gender and age variables. To analyze the dependence of measured quantities on age, participants were grouped according 
Table 1. Table of measured durations and frequencies.

\begin{tabular}{|l|c|c|c|c|c|c|c|c|c|c|}
\hline & \multicolumn{5}{|c|}{ H } & \multicolumn{5}{c|}{ S } \\
\cline { 2 - 12 } & $t 1[\mathrm{~s}]$ & $t 2[\mathrm{~s}]$ & $t 3[\mathrm{~s}]$ & $\Sigma t[\mathrm{~s}]$ & $\Sigma f[\mathrm{~Hz}]$ & $t 1[\mathrm{~s}]$ & $t 2[\mathrm{~s}]$ & $t 3[\mathrm{~s}]$ & $\Sigma t[\mathrm{~s}]$ & $\Sigma f[\mathrm{~Hz}]$ \\
\hline Average & 6.5 & 13.9 & 7.6 & 28.0 & 1.5 & 4.7 & 11.3 & 5.9 & 21.9 & 1.5 \\
\hline Minimum & 1.2 & 3.1 & 0.8 & 7.8 & 0.8 & 0.2 & 2.5 & 1.6 & 6.6 & 0.9 \\
\hline Maximum & 17.7 & 62.0 & 34.5 & 78 & 2.9 & 11.5 & 40.1 & 21.3 & 52.3 & 2.9 \\
\hline SD & 4.0 & 9.7 & 6.1 & 15.0 & 0.5 & 3.1 & 7.9 & 3.7 & 11.1 & 0.6 \\
\hline
\end{tabular}

$\mathrm{H}$ - hard food, S - soft food; $t 1$ [s], $t 2$ [s] and $t 3$ [s] - phase durations (chopping, grinding, swallowing); $\Sigma t$ - summation of $t 1, t 2$ and $t 3 ; \Sigma f$ - total frequency; Average - arithmetical average of measured quantity; Max, Min - maximal and minimal value of measured quantity; SD - standard deviation of measured quantity.

Table 2. Table of evaluated amplitudes.

\begin{tabular}{|l|c|c|c|c|c|c|}
\hline \multirow{2}{*}{} & \multicolumn{3}{|c|}{ Amp H [\%] } & \multicolumn{3}{c|}{ Amp S [\%] } \\
\cline { 2 - 7 } & $\mathrm{x}$ & $\mathrm{y}$ & $\mathrm{z}$ & $\mathrm{x}$ & $\mathrm{y}$ & $\mathrm{z}$ \\
\hline \multirow{2}{*}{ Average } & 56.79 & 35.94 & 66.18 & 58.04 & 41.53 & 69.43 \\
& $(54.90)$ & $(34.61)$ & $(53.87)$ & $(57.04)$ & $(38.98)$ & $(56.41)$ \\
\hline \multirow{2}{*}{ Median } & 55.69 & 33.48 & 55.63 & 54.51 & 35.87 & 62.45 \\
& $(54.35)$ & $(33.41)$ & $(50.32)$ & $(54.26)$ & $(35.86)$ & $(52.04)$ \\
\hline \multirow{2}{*}{ Minimum } & 21.79 & 16.67 & 12.05 & 30.87 & 17.41 & 11.4 \\
\hline \multirow{2}{*}{ Maximum } & 102.44 & 100.95 & 175.93 & 107.02 & 166.75 & 156.10 \\
& $(98.54)$ & $(78.92)$ & $(98.93)$ & $(92.81)$ & $(97.14)$ & $(97.02)$ \\
\hline \multirow{2}{*}{ SD } & 19.71 & 15.01 & 36.29 & 16.22 & 22.93 & 36.38 \\
& $(17.78)$ & $(11.91)$ & $(21.82)$ & $(14.78)$ & $(14.49)$ & $(24.31)$ \\
\hline
\end{tabular}

tH [s], tS [s], AmpH [\%], Amp S [\%]; Average - arithmetical average of measured quantity; Median - median value of measured quantity; Max, Min - maximal and minimal value of measured quantity; Standard deviation - standard deviation of measured quantity; $\mathrm{x}, \mathrm{y}, \mathrm{z}$ - value of Amp 1 and Amp 2 in local coordinated system; values in parenthesis - eliminated values of Amp1 and Amp2 after elimination of values overlapping $100 \%$.

Table 3. Table of gender and age distribution.

\begin{tabular}{|c|c|c|c|}
\hline Age group & Men & Women & Total \\
\hline $20-30$ & 12 & 16 & 28 \\
\hline $31-40$ & 3 & 7 & 10 \\
\hline $41-50$ & 2 & 4 & 6 \\
\hline $51-70$ & 1 & 3 & 4 \\
\hline
\end{tabular}

decades (Tab. 3). Paired and unpaired Student t-test and Fischer's Exact Probability Test rendered the statistical significance. The age criterion was evaluated using ANOVA.

\section{RESULTS}

The chewing movements of 55 subjects with natural dentition were recorded. Owing to problems related to the sensor attaching to the front teeth, records of four subjects could not be used for the analysis. Therefore, statistic analyses were performed on the remaining 51 subjects.

The path of the sensor rigidly connected to the lower jaw was graphically expressed in all axes $(x, y, z)$ for each subject and for each measured motion (hard bite $-\mathrm{H}$, soft bite - S) (Fig. 3). Curves of the mandibular movement trajectory showed that masticatory movements are markedly individual (Fig. 3, 4 and 5). Many of the curves could be easily segmented into phases of bolus chopping, 

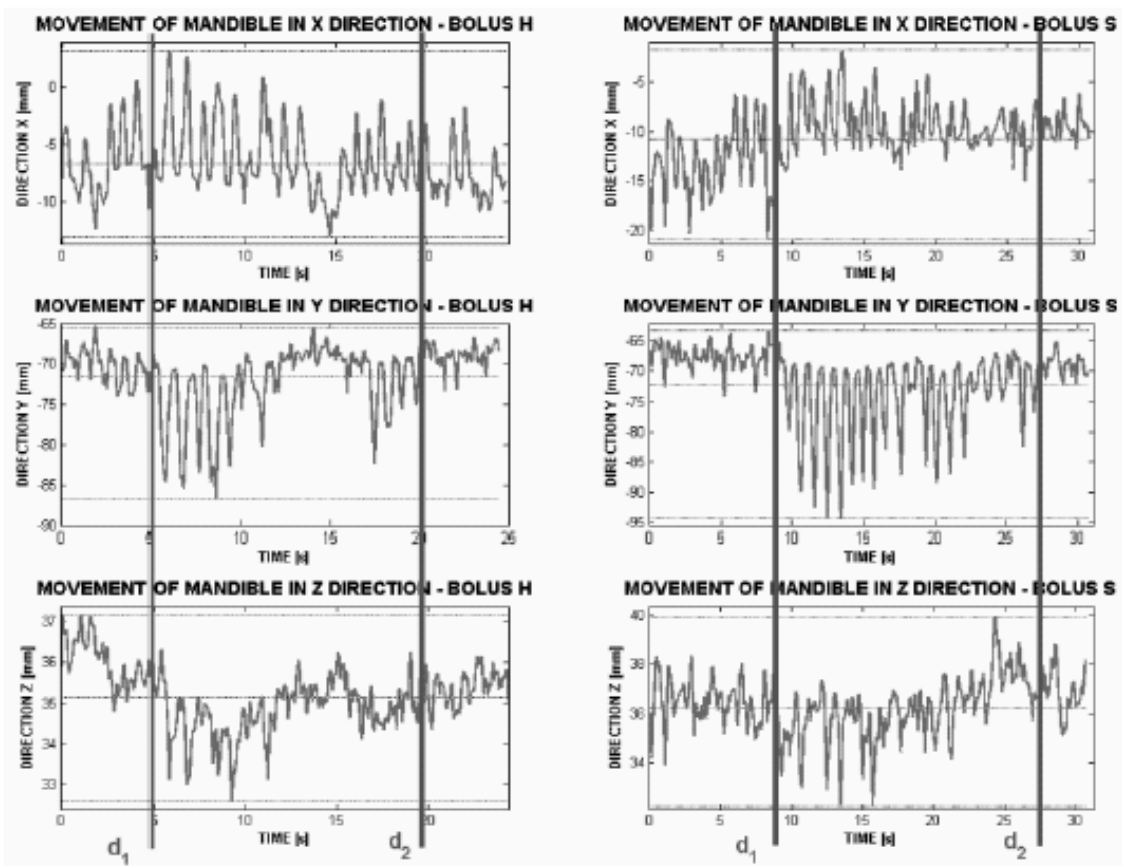

Fig. 3. An example of the lower jaw motion during $\mathrm{H}$ and $\mathrm{S}$ bite processing in the local coordinated system
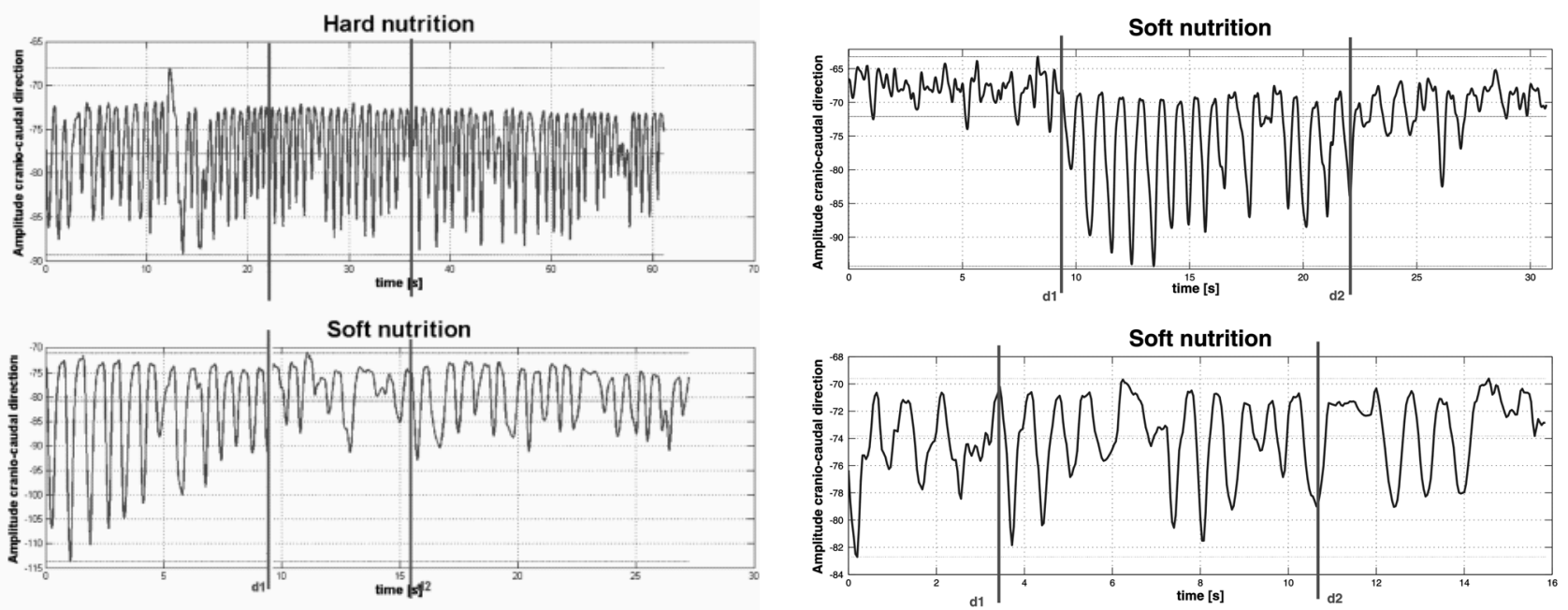

Fig. 4. Typical trajectory of chewing movements of one patient (in $y$ axis) divided into three stages to illustrate the individuality of the bolus processing.

grinding and swallowing (Fig. 3, 4 and 5). Conversely, some subjects chewed in the same manner most of the time (Fig. 4). Also the bolus character influenced the trajectory of lower jaw movements (Fig. 5).

Computed results (average, maximal and minimal values, SD) of particular quantities are shown in Table 1. The average duration for the hard bolus processing was $28.0 \mathrm{~s}(\mathrm{SD}-15.0 \mathrm{~s})$, and for the soft bolus it was 21.9 $\mathrm{s}(\mathrm{SD} \pm 11.1 \mathrm{~s})$. A minimal duration of the bolus processing was $7.8 \mathrm{~s}$ for the hard food and $6.6 \mathrm{~s}$ for the soft food; maximal durations were $78.0 \mathrm{~s}$ and $52.3 \mathrm{~s}$, respectively. The frequency of closing movements (f) for both boluses

Fig. 5. Typical trajectory of chewing movements of two different patients (in $y$ - cranio-caudal axis) divided into three stages to illustrate the individuality of the bolus processing

was 1.5 ( $\mathrm{SD} \pm 0.5$ for hard bolus, $\mathrm{SD} \pm 0.6$ for soft bolus).

Average and median value (in brackets) of amplitude of hard bolus (Amp H) was $56.79 \%(55.69 \%)$ in $\mathrm{x}$ direction, $35.94 \%$ (33.48 \%) in y direction and $66.18 \%$ $(55.63 \%)$ in $\mathrm{z}$ direction. In the case of 8 patients peak values of marginal movements were exceeded (Amp H > $100 \%$ ). Removing these peak values for 2 patients in the $\mathrm{x}$ direction, 1 patient in the y direction and 8 patients in the $\mathrm{z}$ direction, led to a reduction in average (median) value to $54.90 \%(54.35 \%), 34.61 \%(33.41 \%)$ and $53.87 \%$ $(50.32 \%)$ in the $\mathrm{x}, \mathrm{y}$ and $\mathrm{z}$ coordinates. 
Average (median) value of Amp S bolus was $58.04 \%$ (54.51\%) in $\mathrm{x}, 41.53 \%$ (35.87\%) in y and $69.43 \%$ $(62.45 \%)$ in the $z$ direction. The peak values of marginal movements were exceeded (Amp S > 100\%) in the case of 1 patient in the $\mathrm{x}$ direction, 1 patient in the $\mathrm{y}$ direction and in the case of 9 patients in the $\mathrm{z}$ direction. Therefore the average (median) value was reduced to $57.04 \%$ (54.26\%), $38.98 \%(35.86 \%)$ and $56.41 \%(52.04 \%)$ in the $\mathrm{x}, \mathrm{y}$ and $\mathrm{z}$ directions.

The data shown above support the first two hypotheses that the bolus character influences the process duration. The hard bolus was chewed significantly longer than the soft one $\Sigma t(H)>\Sigma t(S)(\mathrm{p}=0.001)$. Also, the duration of the each stage of hard bolus processing was longer than those for the soft bolus. This difference was statistically significant for $t 1(H)>t 1(S)(\mathrm{p}=0.005)$ and $t 2(H)$ $>t 2(S)(\mathrm{p}=0.025)$, but not for $t 3(H)>t 3(S)(\mathrm{p}=0.064)$. The third hypothesis regarding the influence of the bolus character on the frequency of closing movements during the mastication $(f(H)>f(S))$ was not supported; the same average number was achieved for both types of boluses (Fig. 6). Only during the swallowing phase, the frequency of closing movements was significantly higher $(p=0.003)$ for the hard bolus than for the soft one. Neither gender nor age had any influence on either time or frequency of bolus processing, so hypotheses IV. and V. are not confirmed.

\section{DISCUSSION AND CONCLUSION}

The results of this motion analysis confirm data from a similar study ${ }^{1}$ on the influence of individual chewing habits. The overall motion of the point in the defined coordinated system can be used to reconstruct the 3D motion. The design of the experiment using one marker as a mandible position-reading instrument sufficiently served as detection of translational degrees of freedom. Three markers were used ${ }^{1}$ in order to detect the rotational and the translational degrees of freedom, but rotational movements were not useful for the evaluation of the jaw movement parameters.

Exceeding the marginal movement values (Amp H, Amp S > $100 \%$ ) could be explained in 2 ways. First, some patients did not achieve the maximal limited position of marginal movements during the recording. Second, a slightly abnormal mandible movement during mastication was used, owing to the sensor placement. Both, sensor placement and unusual movements to the maximal limited positions could be alter naturally occurred motions ${ }^{1}$. Different numbers of patients exceeding marginal movement's values for different chewing patterns support both explanations.

The hypotheses that the bolus character affects the processing duration were confirmed. The results show the individual variability in timing of the chewing maneuver, especially during the chopping and grinding phases. Comparing the levels of significance for the duration of individual phases, there is a larger difference for the first
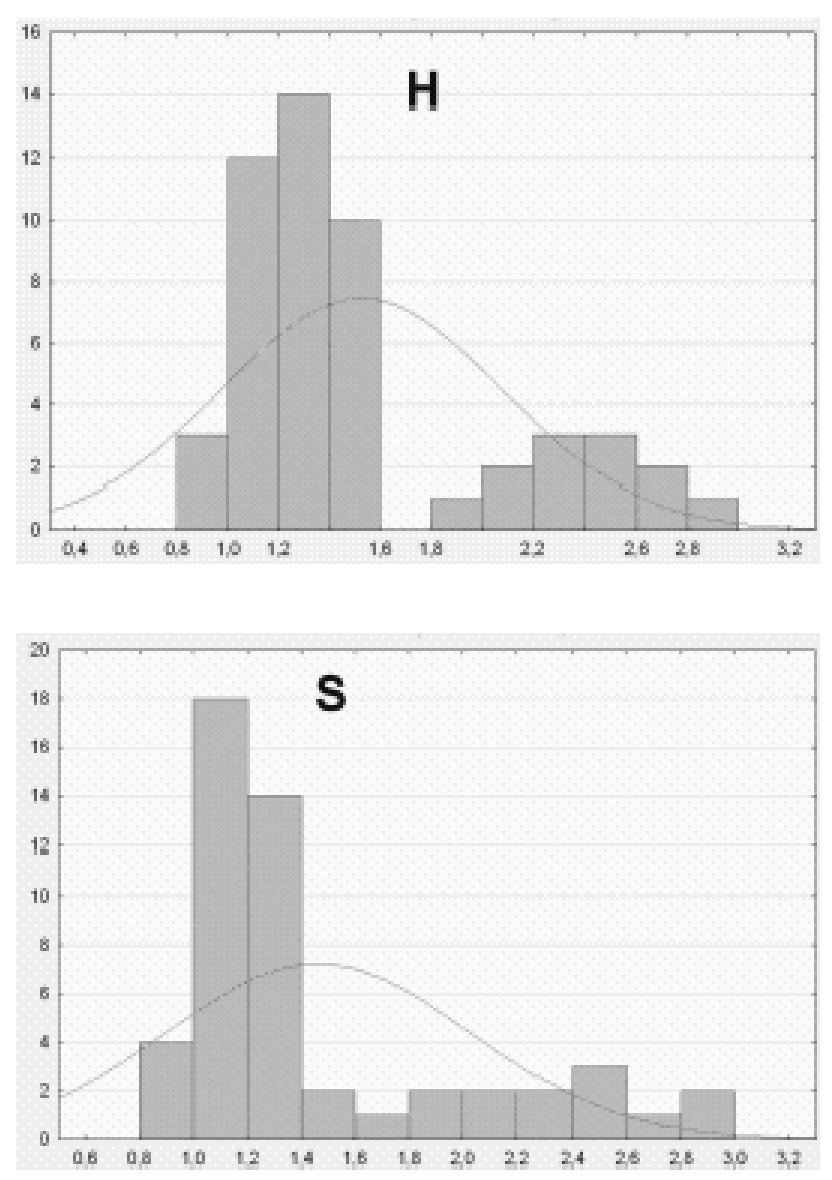

Fig. 6. Histograms of closing movement frequencies during mastication of boluses of different hardness (H - hard, S - soft)

phase-chopping $(\mathrm{p}=0.005)$ than for the grinding phase $(\mathrm{p}=0.025)$.

The same frequency during mastication indicates that the bolus character does not influence masticatory movements. A significant difference between frequencies was found during swallowing only and could reflect the different textures of pastry and nuts (fine particles) at the time of swallowing. Alternatively, this finding could have been influenced by salivation.

This difference between time and frequency is unexpected. It suggests that time and frequency of mastication closely correlate and that crushing food to the desired texture is controlled mostly by time of processing. Only when bolus is finally crushed, strokes with small and decreasing amplitude (Fig. 3, 4, 5) allow higher frequency for chewing of hard bolus and therefore further time is unnecessary. It was also unexpected that both, gender and age did not influence time and frequency of bolus processing.

These findings agree with the theory that mastication is a highly individual process influenced not only by anatomy, but also by a specific manner developed during life. Similar findings were performed by Gerstner ${ }^{1}$.

The observed decrease of the amplitude in cranio-caudal (opening, closing) movements support the hypothesis 
that the stage of the bolus processing influences the shape of the curve illustrating movement of the mandible and thus the direction of the actual chewing force. Computed trajectories agree with observations by Bhatka ${ }^{4}$ that the center of lower jaw motion moves along an elliptically shaped curve.

Understanding masticatory development and physiological relationships are important in determining the principal anatomical direction during closing movements and the resultant direction of the loading during mastication. Such findings can be used to plan treatment and to reconstruct defective dentition from a masticatory point of view, as well as to validate treatment procedures. Results can also affect the design and the usage of materials for the dental implants, their position in jaws and the shape of the occlusal surface of bridgeworks and dentures.

The information obtained in this pilot study suggest that masticatory movements vary by individual and that their relationship to the direction and the magnitude of the chewing force should be more precisely examined.

\section{ACKNOWLEDGEMENT}

The research has been supported by the Ministry of Education project No. MSM 6840770012 and by the Grant Agency of the Czech Republic under project No. 106/06/0849.

\section{REFERENCES}

1. Gerstner GE, Lafia C, Lin D. Predicting masticatory jaw movements from chin movements using multivariate linear methods. J Biomech 2005; 38:1991-9.

2. Klepáček I, Mazánek J. Klinická anatomie ve stomatologii. Grada Publishing, Avicenum, Praha, 2001.

3. Voldřich M. Stomatologická protetika. Státní zdravotnické nakladatelství, Praha, 1969.

4. Bhatka R, Throckmorton GS, Wintergerst AM, Hutchins B, Buschang PH. Bolus size and unilateral chewing cycle kinematics. Arch Oral Biol 2004; 49:559-66.

5. Eskitascioglu G, Usumez A, Soykan E, Unsal E. The influence of occlusal loading location on stresses transferred to implant-supported prostheses and supporting bone: a three-dimensional finite element study. J Prosthet Dent 2004; 91:253-257.

6. Blanksma NG, van Eijden TM, van Ruijven LJ, Weijs WA. Electromyographic heterogeneity in the human temporalis and masseter muscles during dynamics tasks guided by visual feedback. J Dent Res 1997; (76):542-551.

7. van der Helm FCT, Veenbaas R. Modelling the mechanical effect of muscles with large attachment sites: application to the shoulder mechanism. J Biomech 1991; 24:1151-1163.

8. Koolstra JH, van Eijden TM. Three-dimensional dynamical capabilities of the human masticatory muscles. J Biomech 1999. 32:145-152.

9. Prinz JF. The Cybermous: A simple method of describing the trajectory of the human mandible in three dimensions. J Biomech 1997; 30:643-645.

10. Zatsiorski VM. Kinematics of Human Motion. Human Kinetics, Champaign, IL, 1998.

11. Abdel-Aziz YI, Karara HM. Direct linear transformation from comparator co-ordinates into object space co-ordinates. Proceedings ASP/UI symposium on close-range photogrammetry, Am. Soc. of Photogrammetry, Falls Church, VA, 1971; p. 1-18. 